\title{
A Survey on the Use of Benchmarking as a Continuous Improvement Tool for Ministry of Agriculture Parastatals in Kenya
}

\author{
Akuma Enosh Ongosi, Peterson Obara Magutu, Richard Nyaanga Ongeri, \\ Robert Matwere Bosire and Tamaro Abuya Mogendi
}

\begin{abstract}
The study aimed at establishing the application of benchmarking as a tool for continuous improvement within Parastatals in the Ministry of Agriculture in Kenya. The study used descriptive research in its methodology. The study took the design of a survey. Data collection was effected by use of structured questionnaires, which targeted senior, middle-level management and the equivalent. The targeted population was the 24 parastatals with the Ministry of Agriculture in Kenya. The questionnaire was self-administered through the drop and-pick approach, coded, checked for any errors and omissions. The study established that certain challenges need to be addressed within the Ministry of Agriculture parastatals; comparability of the parastatals and their operation processes, seeking aid and support from sources and institutions that might be able to point to and convince potential partners, finding benchmarking collaborators willing to participate in the benchmarking studies, applying a systematic procedure whereby a large number of potential benchmarking partners are scanned for relevance and high performance, exchanging all possible background information beforehand. The other challenges with a mean of three seem to be coupled with uncertainties on their influence on the success of the benchmarking technique as a tool of continuous improvement. Delays in remission of questionnaires was experienced, submission of irrelevant information, transportation difficult given the location of some of the parastatals, and challenges were encountered in undertaking literature review given the poorly equipped laboratories with ICT and e-operations.
\end{abstract}

Index Terms - Benchmarking, Continuous Improvement Tool, Ministry of Agriculture, Parastatals \& Kenya.

\section{INTRODUCTION}

In order for government corporations to attain continuous improvement in the service delivery to the citizenry, there is need for the utilization of service improvement tools of which one of the tools is benchmarking. [1] observes that a benchmark is a standard of excellence against which to compare and measure. Benchmarking is observed to have traversed four generations, namely, reverse engineering, competitive benchmarking, process benchmarking and strategic benchmarking. Strategic benchmarking being a systematic process for evaluating alternatives and adopting

Published on December 30, 2020.

Akuma Enosh Ongosi, Postgraduate Student, Department of Management Science, University of Nairobi, Nairobi, Kenya.

(corresponding e-mail: enoshakuma@yahoo.com)

Peterson Obara Magutu, Department of Management Science, University of Nairobi, Nairobi, Kenya.

(e-mail: magutumop@uonbi.ac.ke)

Richard Nyaanga Ongeri, Postgraduate Student, Department of Management Science, University of Nairobi, Nairobi, Kenya.

(e-mail: nyaangarichardo@gmail.com) external partners successful strategies. The climax in benchmarking is when one makes fundamental shifts in a process that needs re-engineering [2].

Benchmarking entails comparing one's business process with "best practices" which are documented strategies and tactics employed by highly admired companies. These are companies, which are most profitable and are the strongest competitors in their businesses [3]. Benchmarking is a multifaceted technique that can be utilized to identify operational and strategic gaps and to search for best practices aimed at eliminating such gaps. Of importance is having proper framework of mind of receiving the lessons of benchmarking [3]. The authors further observe that benchmarking is one of the most effective means to identify improvements, which can make a significant difference to an organization.

Sources of benchmarking ideas can be obtained from data centers, libraries or through direct search [4]. [5] concluded that the three critical factors that have influenced the success of public universities' benchmarking practices in their environs are time and resource availability: limited duration, comparability and compatibility, which is the reason why companies do not practice international benchmarking. [6] and [5] also recommended a study towards determining the extent to which other companies and institutions outside the higher education sector have used benchmarking as a tool for continuous improvement.

The Ministry of Agriculture is of the government ministries in which 24 parastatals have been established for such specialized services. A scan on the parastatals' performances reveals extremes in their performance with a huge gap between top performers and poor performers in the quality of service delivered. One wonders to what extent benchmarking may have been applied as a technique in attainment of quality service delivery amongst the Ministry of Agriculture parastatals [8]. There was need to investigate the challenges facing the 24 Ministry of Agriculture parastatals in the use of benchmarking as a continuous improvement tool towards excellent service delivery.

Robert Matwere Bosire, Postgraduate Student, Department of Management Science, University of Nairobi, Nairobi, Kenya.

(e-mail: matwerebosire ${ }^{\circledR}$ gmail.com)

Tamaro Abuya Mogendi, Postgraduate Student, Department of Management Science, University of Nairobi, Nairobi, Kenya.

(e-mail: tamaroabuya ${ }^{\circledR}$ gmail.com) 


\section{RESEARCH PROBLEM}

Various ministries of the Kenyan Government have parastatals, which are also referred to as state corporations. The Government has established these state corporations for specialized services and management of certain specialized strategic functions that demand government involvement. The public sector department and parastatals undertake a comparative analysis of their performance outcomes and learn from each other hence the application of the concept of benchmarking. The Government collects taxes and levies other fees which are appropriated to the parastatals through annual budgets for service delivery [8].

A number of researches in benchmarking have been undertaken in the past. [7] found out that benchmarking can support very different agenda driven by a need to learn in order to understand, improve and innovate; a collective commitment to self- determined improvement even in competitive market - a new collegiality and models of working that are based on professional rather than public accountability.

Among the local studies, [6] focused on benchmarking the order delivery process for continuous improvement in the Kenya oil industry, and [5] documented the benchmarking activities based on the academic function of Kenya public universities, both studies suggested that there was need for a study to be conducted to determine to what extent other companies outside the oil and education industries in Kenya use benchmarking as a continuous improvement tool.

Although researches had been conducted on benchmarking, none had been conducted on the 24 Ministry of Agriculture parastatals in Kenya. This study therefore sought to investigate and document the challenges that were facing the Ministry of Agriculture parastatals in the use of the benchmarking technique as a continuous improvement tool to learn from the best performers, internally and externally, to achieve improvements in their own processes.

\section{RESEARCH OBJECTIVES}

The research was conducted with the overall objectives of establishing the extent of adoption of benchmarking technique as a tool for continuous improvement in the Ministry of Agriculture Parastatals in Kenya and the challenges facing the Ministry of Agriculture parastatals in Kenya in the use of benchmarking technique as a tool for continuous improvement.

\section{LITERATURE REVIEW}

The existing literature on the use of benchmarking for continuous improvement is what makes up this section. The literature review documented findings on past studies on the use of benchmarking as a continuous tool for improvement.

The Literature review documented definitions of benchmarking, origins of benchmarking, best practices, continuous improvement, evolution of benchmarking, types of benchmarking as well as challenges encountered during benchmarking.

\section{A. Benchmarking}

Benchmarking is recognized as an essential tool for continuous improvement of quality. Originally the term "benchmark" derives from land surveying where a mark, cut in the rock, would act as a point of reference. In the business world, a benchmark is a standard of excellence against which to measure and compare [1].

Benchmarking is continuous search for, and application of significantly better practices that lead to superior competitive advantage. [9] defines benchmarking as a disciplined process that begins with a thorough search for to identify best practices, continues with the careful study of one's own practices and performance, progresses through systematic site visits and interviews and concludes with the analysis of results, development of recommendations and implementation.

[10] defines benchmarking as the systematic identification of the best practices employed by other jurisdictions which lead to superior performance. Benchmarking can somewhat philosophically be defined as follows [11]; Benchmarking is the process of being humble enough to admit that someone is better at something and being wise enough to learn how much to match them and even surpass them."

\section{B. Statistical Definition of Benchmarking}

The term benchmarking also has a statistical definition. It is a method of using auxiliary information to adjust the sampling weights used in an estimation process in order to yield more accurate estimates of totals [12].

In reviews of literature, it was established that six literature reviews have been made in benchmarking in the past. The literature reviews document that benchmarking has gone through four distinct generations, namely reverse engineering, competitive benchmarking, process benchmarking and strategic benchmarking.

Benchmarking entails comparing one's business process with "best practices" which are documented strategies and tactics employed by highly admired companies. These are companies which are most profitable and are the strongest competitors in their businesses [3].

\section{Benchmarking and Continuous Improvement}

Benchmarking is about examining others and finding how they attain their improvement. Improvement is defined as providing an incremental customer satisfaction in the most effective manner. Continuous improvement adopts an approach to improving performance which assumes more and smaller improvement steps. In continuous improvement it is not the rate which matters but the momentum of improvement [12].

Sources of information about other organizations can be obtained from data centers, libraries, or direct contact [4]. Benchmarking as a method of self - assessment is based on two different ideas: referencing and comparing one thing with another and searching for and creating reference points or benchmarks. There are four different reference processes that can be distinguished [7]; Action research; focused surveys supported with discussions; Performance indicators statistical measures and online databases; specification, codes of practice, descriptors, and examples of good practice; performance criteria and scoring systems; standardized 
testing examples of performance.

[1] Scrutinized the historical development of Benchmarking concepts and suggests that Benchmarking is moving from an art to a science. Benchmarking has evolved in four phases, namely reverse engineering, competitive benchmarking, process benchmarking and finally strategic benchmarking. Strategic benchmarking takes longer to undertake, can lead to fundamental shifts in process, takes more resources and results to process re-engineering [13].

Benchmarking activities can be classified according to the nature of processes that underpin the activity [7] and/or whether the process is implicit or explicit; conducted as independent or collaborative or partnership; confined to a single organization internal or involves other similar or dissimilar organizations - externa; focused on the whole process or part of a process. There are seven standard types of benchmarking, namely Generic benchmarking, Internal benchmarking, external /best practice benchmarking, strategic benchmarking, competitive benchmarking, process benchmarking, international benchmarking.

Benchmarking as an undertaking may face certain challenges to organizations seeking to improve their performance. Benchmarking is a moderately expensive process and can lead to imitation of best practices without critical reflections resulting to lack of innovation inside organization machinery. The following are four factors noted by [14] and [4] that influence benchmarking decisions; Compatibility with local conditions, comparability of companies and processes, time and resource availability, limited duration for in depth engagements, level of experience and determination of objectives to be achieved and aspects to be reviewed.

The above act as challenges to benchmarking but information technology has been utilized to support logistics and grow rapidly with the introduction of microcomputers in the early 1980s [14]. The study was based on the above challenges while evaluating the parastatals.

Benchmarking procedures include a number of steps, namely identify problem areas, identify lead organizations in the area of focus, survey identified companies for measures and practices, visit the best practice company and identify leading edge practices. Implement new and improved business practices. According to [7], benchmarking results to three different products, namely improved networking, collaborative relationship, and mutual understanding between participants; benchmarking information, a better understanding of the best practice.

\section{ReSEARCH MethodOLOGY}

This section is about the design of the research, the population, and the sample which was selected for the study. The section further highlights the techniques which were used for data collection and presentation.

The research design adopted was a survey on the adoption and challenges facing the Ministry of Agriculture parastatals in Kenya in the use of benchmarking technique as a tool for continuous improvement. A survey research design was chosen because of the manageable number of parastatals under the Ministry of Agriculture; a total of twenty four (24) in number.
The targeted population was all the twenty four parastatals under the Ministry of Agriculture from which a sample was drawn. Sampling involved gathering of data or opinions considered representative of the whole. This study therefore constituted all the parastatals in the Ministry of Agriculture which was possible because of the number 24 was manageable.

The unit of analysis was the parastatal's operation function and sixty two (62) respondents were sampled. [15] proposes a rule of the thumb for determining a sample size and says that a sample size of 30 to 500 is appropriate for most researches.

The study relied on primary data which was collected through application of questionnaires. The data collection entailed distribution of questionnaires in the operations functions of the Ministry of Agriculture parastatals. The sample frame constituted of the three levels of management in the Ministry of Agriculture parastatals that is the senior, Middle and Low level management. The questionnaire were self-administered in that it involved the 'drop-and -pick later' approach. This gave respondents ample time to time through the questions before answering them.

Completed questionnaires were edited for completeness and consistency. The data then was coded and checked for errors and omissions [16] and then analyzed using procedures within statistical Package for Science (SPSS) - PC Version 11 to get its feel. One basic form of analysis was performed that is simple descriptive univariate statistics.

The responses from open ended questions were listed so as to obtain proportions appropriately; the mean and standard deviation were used. The mean was to measure the average response of the population. The mode was used as an arithmetic measure of the most frequently identified observation. The standard deviation was to look at the spread of the answers to the mean. For closed questions, a comparative analysis using distribution tables, quantiles (percentiles) and graphical analysis was undertaken to ascertain whether there was a significant difference within the pattern of responses and to improve the presentation of the analyzed results for ease of interpretation.

To establish the most critical challenges, factor analysis techniques were used to approximate each set of variables/challenges relative to others; factor analysis was used to reduce a large amount of data into a structure that can be more easily studied.

\section{Data Analysis, Findings AND Discussions}

\section{A. Introduction}

This section entails data analysis and findings of the research. The data is presented in form of proportions, means, tables and graphs. Data was collected from 24 parastatals of the Ministry of Agriculture whose performance is at extremes. The collected data has been analyzed and interpreted in line with the aims of the study. Out of the sixtytwo (62) respondents to whom the questionnaires were administered, only thirty-five (35) respondents in the parastatals responded. This gave a response rate (RR) of 56\%. This RR is in line with [17] whose research recommends that RR for middle level managers studies should be $60 \%+/-20 \%$. 


\section{B. Organizational Profile}

Public organizations have their policies on resource utilization pegged on wider framework of effective use of public resources and provision of information to drive change to the government for social and economic agenda. The respondents ranked their parastatals in some key performance aspects on a scale of 1 to 5 . The results are as displayed in Table 1 below.

TABLE 1: THE COMPARISON AND EvAluATION OF THE PRACTICES, PROCESSES AND PERFORMANCE

\begin{tabular}{lccc}
\hline \multirow{2}{*}{$\begin{array}{l}\text { Evaluation of the Practices, Processes } \\
\text { and Performance }\end{array}$} & \multicolumn{2}{c}{$\begin{array}{c}\text { Descriptive } \\
\text { Statistics }\end{array}$} & \multirow{2}{*}{ Rank } \\
\cline { 2 - 3 } & Mean & $\begin{array}{c}\text { Std. } \\
\text { Dev }\end{array}$ & \\
\hline $\begin{array}{l}\text { Effective use of public resources } \\
\text { Provision of information to the public } \\
\text { to enable them make informed choice }\end{array}$ & 2.8857 & 0.90005 & 1 \\
$\begin{array}{l}\text { Provision of information to drive } \\
\text { change to the government for social } \\
\text { and economic agendas }\end{array}$ & 2.4286 & 1.17180 & 2 \\
$\begin{array}{l}\text { Your ability to meet market } \\
\text { requirements }\end{array}$ & 2.6000 & 1.11672 & 3 \\
\hline
\end{tabular}

From the results it was ascertained that the parastatals to a very great extent $($ mean=1) made effective use of public resources; and to a great extent $(\mathrm{Mean}=2)$ provided information to the public to enable them to make informed choice and information to drive change to the government for social and economic agendas; and at least met market requirements.

\section{The extent of adoption of Benchmarking Technique as a tool for continuous Improvement}

In order to establish the extent of adoption of benchmarking technique as a tool for continuous improvement in the Ministry of Agriculture parastatals in Kenya, some issues were analyzed as below.

1. Continuous Improvement Systems in the Ministry of Agriculture Parastatals in Kenya

The respondents were asked to make an assessment of the continuous improvement systems in their organizations and the responses are explained as below.

The respondents were asked to rate their parastatals services congruence with the market requirements and the marketability of their products and services. From the research data, the congruence parastatals products and services with the market requirements and the marketability of products and services was ranked as good with $57 \%$, and excellent with $29 \%$. This was clear indication that some $14 \%$ of the parastatals were below average. The respondents were also asked to rate the continuous improvement systems in the parastatals, from the research data, $55 \%$ of the respondents indicated them as good, as $45 \%$ indicated them as fair. This confirms [18] conclusion that the Kenyan people are not receiving value for their money instead what can be seen are poorly performing state corporations and government departments full of corruption.

The respondents were also asked to indicate how often the improvement practices were renewed/reviewed. From the research data, $38 \%$ indicated that they are renewed annually, as the rest renewed biannually. Hence, they meet the definition of continuous improvement. Some of the external drivers of change in the parastatals were found to be marketplace, Customers and Legislation. The internal drivers of change in the parastatals were also found to be Actual Performance and Monitoring systems.

\section{Benchmarking Practices}

On the existence of benchmarking practices, the respondents were asked to indicate whether there are systems that facilitate the systematic comparison and evaluation of practice, process, and performance with any "best practice or smarter" institutions in improvement and self-regulation. From the research data, $60 \%$ of the respondents indicated that they had such systems in place. Development and improvement purposes was the major reason for the systematic comparison and evaluation of practice, process, and performance with any "best practices or smarter" institutions for parastatals.

The respondent was asked to indicate the comparison and evaluation of the practice, process, and performance on a scale of 1 to 5 . From the results in Table 2 below, some of the systematic comparison and evaluation of the practice, process and performance that have been adopted to a great extent $(\mathrm{Mean}=2)$ in are respondents were found to be; an analysis of results; measurement, of own and benchmarking partners' performance level, both for comparison and for registering improvements; comparison of performance levels, processes and practices; the careful study of your own practices and performance; and lastly a thorough search to identify bestpractice-organizations. The respondents also indicated that public capacity of the systems to develop, improve, and regulate itself drives the agenda of learning, improvement, innovation and change towards a self-determined improvement. This is the true picture of public institutions.

TABLE 2: The CoMPARISON AND Evaluation of THE PRACTICE, PROCESS AND PERFORMANCE

\begin{tabular}{|c|c|c|c|}
\hline \multirow{2}{*}{$\begin{array}{l}\text { Evaluation of the practices, } \\
\text { processes, and performance }\end{array}$} & \multicolumn{2}{|c|}{ Descriptive Statistics } & \multirow{2}{*}{ Rank } \\
\hline & Mean & S. Dev & \\
\hline An analysis of results & 2.2759 & 1.19213 & 1 \\
\hline $\begin{array}{c}\text { Measurement of own and } \\
\text { benchmarking partners }\end{array}$ & & & \\
\hline $\begin{array}{l}\text { performance level, both for } \\
\text { comparison and for registering } \\
\text { improvements }\end{array}$ & 2.3030 & 1.10354 & 2 \\
\hline $\begin{array}{l}\text { Comparison of performance } \\
\text { levels, processes, practices, etc }\end{array}$ & 2.4375 & 1.10534 & 3 \\
\hline $\begin{array}{l}\text { The careful study of your own } \\
\text { practices and performance }\end{array}$ & 2.4839 & 1.26151 & 4 \\
\hline $\begin{array}{l}\text { A thorough to find identify best- } \\
\text { practice organizations }\end{array}$ & 2.5000 & 1.23228 & 5 \\
\hline $\begin{array}{c}\text { Systematic site visits and } \\
\text { interviews }\end{array}$ & 2.5000 & 1.34715 & 6 \\
\hline $\begin{array}{l}\text { Development of } \\
\text { recommendations and } \\
\text { implementation }\end{array}$ & 2.5000 & 1.22474 & 7 \\
\hline $\begin{array}{l}\text { Learning from the benchmarking } \\
\text { partners to introduce } \\
\text { improvements in your own } \\
\text { organization }\end{array}$ & 2.6333 & 1.18855 & 8 \\
\hline $\begin{array}{l}\text { Improvement which is the } \\
\text { ultimate objective of any } \\
\text { benchmarking study }\end{array}$ & 2.6333 & 1.12903 & 9 \\
\hline
\end{tabular}

There are a number of factors that influence the success of the benchmarking/process of emulating the best practices. The respondents were also to indicate the factors that influence the benchmarking process of emulating the best practices in the parastatals on a scale of 1 to 5 . The results are 
as indicated in Table 3 below.

D. The Factors that Influence the Success of the Benchmarking/the Process of Emulating the Best Practices

TABLE 3: FACTORS THAT INFLUENCE THE SUCCESS OF BENCHMARKING

\begin{tabular}{llccc}
\hline $\begin{array}{l}\text { Factors that influence the success of } \\
\text { benchmarking }\end{array}$ & \multicolumn{3}{c}{ Descriptive Statistics } & \\
\cline { 2 - 3 } & Rean & $\begin{array}{c}\text { Std. } \\
\text { Dev }\end{array}$ & \\
\hline $\begin{array}{l}\text { Objective Identification } \\
\text { opportunities and bottlenecks }\end{array}$ & 1.0714 & .26227 & 1 \\
$\begin{array}{l}\text { The organization's own former } \\
\text { performance }\end{array}$ & 1.0968 & .30054 & 2 \\
$\begin{array}{l}\text { The added value offered by the } \\
\text { method /cost - benefit analysis }\end{array}$ & 1.2069 & .41225 & 3 \\
$\begin{array}{l}\text { The support of the method to internal } \\
\text { quality management }\end{array}$ & 1.2333 & .43018 & 4 \\
$\begin{array}{l}\text { The contribution to a greater } \\
\text { accountability by the outside world }\end{array}$ & 1.3333 & .47946 & 5 \\
\hline
\end{tabular}

Source: Research Data.

From the results in Table 3 above, some of the systematic factors that influence the success of benchmarking/ process of emulating best practices in the parastatals to a great extent include the objective of opportunities and bottlenecks; the organization's own performance; the added value offered by the method/cost benefit analysis; the support of the method to internal quality management within; and the contribution to a greater accountability to the outside world. This is in line with [19] observation that benchmarking may not be a one-off event but is often treated as a continuous process in which organizations continually seek to challenge their practices influenced by a number of factors.

A better understanding of practice, performance, and insights to a very great extent is what the parastatals have achieved in the participation in any benchmarking/systematic comparison exercise.

\section{E. The Challenges Facing the Ministry of Agriculture Parastatals in the use of Benchmarking Technique}

\section{How Comparisons are done and modelled}

The respondents were asked to indicate how the comparisons in benchmarking are done and modeled in the parastatals. From the research data, $71 \%$ of the parastatals agreed with the 2006/2007 performance ranking of the Ministry of Agriculture parastatals.

On how the comparisons are done on a scale of 1 to 5 , the results are as in Table 4 below. Most respondents indicated that the comparisons are done through systematic evaluation of alternatives and adopting successful comparing processes with those of competitors in the ministry.

TABLE 4: HOW COMPARISONS ARE DONE

\begin{tabular}{lcc}
\multicolumn{3}{c}{ TABLE 4: HOW COMPARISONS ARE DONE } \\
\hline How Comparisons are Done & Freq. & $\%$ \\
\cline { 2 - 3 } $\begin{array}{l}\text { Systematic evaluation of alternatives and } \\
\text { adopting successfully }\end{array}$ & 20 & 58.8 \\
$\begin{array}{l}\text { Comparing processes with those of } \\
\text { competitors in the Ministry }\end{array}$ & 9 & 26.5 \\
$\begin{array}{l}\text { Learning from companies outside the } \\
\text { ministry of agriculture }\end{array}$ & 3 & 8.8 \\
$\begin{array}{l}\text { Breaking/tearing down the services } \\
\text { offered and technical pro } \\
\text { TOTAL }\end{array}$ & 2 & 5.9 \\
\hline
\end{tabular}

Source: Research Data.

The comparisons can also be modelled in different ways. The respondents were asked to indicate how comparisons are done on a scale of 1 to 5 and the results are shown in Table 5 below.

TABLE 5: COMPARISONS MODELLED

\begin{tabular}{|c|c|c|c|}
\hline \multirow[b]{2}{*}{ How comparisons are modelled } & \multicolumn{2}{|c|}{ Descriptive Statistics } & \multirow[b]{2}{*}{ Rank } \\
\hline & Mean & $\begin{array}{c}\text { Std } \\
\text { Deviation }\end{array}$ & \\
\hline Independent Self Referencing & 1.5667 & .50401 & \\
\hline Collaborative group partnership & 1.8286 & .92309 & \\
\hline $\begin{array}{c}\text { Brokered models (involving an } \\
\text { individual or an agency } \\
\text { intervening) }\end{array}$ & 1.8571 & .80961 & \\
\hline $\begin{array}{c}\text { Collaborative one-to-one } \\
\text { partnership }\end{array}$ & 1.9143 & .70174 & \\
\hline Independent self-referencing & 1.5667 & .50401 & \\
\hline
\end{tabular}

Source: Research Data.

From the results in Table 5, to a very great extent $($ Mean $=$ 1) the comparisons are modelled through independent selfreferencing followed by collaborative group partnership, then through brokered models involving an individual or agency intervening.

2. The Referencing Processes and Type of Benchmarking Schemes Used as a Mechanism for Comparison

The respondents were asked to indicate the extent of use of the different referencing processes used as a mechanism for comparison and the extent of use and awareness of the types of benchmarking schemes. The results were as Table 6 below.

\section{TABLE 6: THE REFERENCING PROCESSES}

\begin{tabular}{lcc}
\hline \multicolumn{1}{c}{ The Referencing process } & \multicolumn{2}{c}{ Distribution } \\
\cline { 2 - 3 } & Freq. & $\%$ \\
\hline Performance Indicators - Statistical measures & 20 & 58.8 \\
and online data & & \\
$\begin{array}{l}\text { Specification, codes of practice, descriptors, } \\
\text { and examples }\end{array}$ & 9 & 26.5 \\
Action Research supported by discussions & 2 & 5.9 \\
TOTAL & 31 & 100 \\
Source: Research Data.
\end{tabular}

From the research data, most respondents indicated that the major source of data and information on benchmarking is through direct contact. From the results in Table 6 above, the reference point for the comparisons are performance indicators that is the statistical measures and online data, as opposed to the specifications, codes of practice, descriptors and examples and action research which is focused surveys supported by discussion.

TABLE 7: TYPES OF BENCHMARKING SCHEMES

\begin{tabular}{|c|c|c|c|}
\hline \multirow[t]{2}{*}{ Types of Benchmarking Schemes } & \multicolumn{2}{|c|}{$\begin{array}{c}\text { Descriptive } \\
\text { Statistics }\end{array}$} & \multirow[t]{2}{*}{ Rank } \\
\hline & Mean & Std. Dev & \\
\hline Internal benchmarking & 1.6400 & 1.03602 & 1 \\
\hline Competitive/Internal benchmarking & 1.6897 & 0.80638 & 2 \\
\hline External benchmarking & 1.8571 & 1.11270 & 3 \\
\hline Strategic benchmarking & 1.8621 & 0.91512 & 4 \\
\hline Process benchmarking & 2.1429 & 1.04401 & 5 \\
\hline Collaborative benchmarking & 2.2000 & 1.00000 & 6 \\
\hline Independent benchmarking & 2.2000 & 1.25831 & 7 \\
\hline International benchmarking & 2.2222 & 1.15470 & 8 \\
\hline $\begin{array}{l}\text { Development/Improvement } \\
\text { benchmarking }\end{array}$ & 2.2400 & 1.12842 & 9 \\
\hline Functional/Generic benchmarking & 2.4074 & 1.11835 & 10 \\
\hline Bureaucratic benchmarking & 3.0000 & 0.86603 & 11 \\
\hline
\end{tabular}

Source: Research Data.

Based on the comparison mechanisms, from the results in Table 7 above, the four types of benchmarking which are 
currently in use are internal benchmarking, competitive/performance benchmarking, external benchmarking, and strategic benchmarking. Also, from the research data, the three most critical factors that influence the choice of the various benchmarking tools and scope in the parastatals were found to be compatibility with local conditions, time, and resources availability and lastly the limited duration for compatibility of the parastatals and processes.

\section{Challenges and Successes of Benchmarking}

TABLE 8: CHALLENGES AND SUCCESSES OF BENCHMARKING

\begin{tabular}{|c|c|c|c|c|c|}
\hline \multirow{2}{*}{$\begin{array}{l}\text { Challenges and } \\
\text { Benchmarking }\end{array}$} & \multirow[t]{2}{*}{ Successes } & \multirow[t]{2}{*}{ of } & \multicolumn{2}{|c|}{$\begin{array}{l}\text { Descriptive } \\
\text { Statistics }\end{array}$} & \multirow[t]{2}{*}{ Rank } \\
\hline & & & Mean & Std.Dev & \\
\hline
\end{tabular}

Analyzing and gaining a deeper

understanding of one's own processes for improvement in the industrial partners in the ministry of agriculture

A need for understanding own processes

by analyzing and understanding the parastatals own processes

Requesting initial performance

information about the processes in

question before selecting a benchmarking partner, to make sure the performance is sufficiently good to offer new insights.

Performing the benchmarking visits in teams to ensure that people complement each other in terms of skills and interests and contribute to creating ownership in the parastatals.

Comparability of companies and processes.

Seeking aid and support from sources and institutions that might be able to point to and convince potential partners, e.g industry associations, area experts, media, etc.

Finding Benchmarking collaborators willing to participate in the benchmarking studies.

Applying a systematic procedure whereby a large number of potential benchmarking partners are scanned for relevance and high performance.

Exchanging all possible background information beforehand, thus being able to start covering the interest parts right away. Getting acceptance for the use of both quantitative and qualitative benchmarking information.

Limited duration of each interview and being limited by time.

Offering to pay for the time spent by the benchmarking partner in preparations for and during the benchmarking visit.

Lack of business process understanding.

Making sure the offer made to the companies is attractive, for instance by informing about processes, the benchmarking company is particularly good at and offering return visits.

The use of a generic benchmarking questionnaire in language in structuring the individual benchmarking reports.

Making sure to bring along someone

fluent in the local language if the benchmarking partner finds it difficult to conduct the interviews in an international language

Meeting for a social gathering the night before the benchmarking visit to break the ice and build up trust before starting the meeting.

Source: Research Data. $2.6897 \quad 1.10529 \quad 3$

$2.7931 \quad 1.11417 \quad 6$

$3.4444 \quad 1.36814 \quad 11$

There are number of factors, that affect/challenge the successes in the use of benchmarking technique as a tool for continuous improvement. The respondents were asked to rank in a scale of 1 to 5 the extent to which some of the key challenges have faced the Ministry of Agriculture Parastatals in Kenya in the use of benchmarking technique as a tool for continuous improvement, and the results are as Table 8 above.

From the results in Table 8 above, the nine key challenges that have faced the Ministry of Agriculture parastatals in Kenya in the use of benchmarking technique as a tool for continuous improvement to a great extent $($ Mean $=2)$ include; analyzing and gaining a deeper understanding of one's own processes, requesting initial performance information about the processes in question before selecting a benchmarking partner, performing the benchmarking visits in teams to ensure that people complement each other in terms of skills and interests, comparability of companies and operational processes, seeking aid and support from sources and institutions that might be able to point to and convince potential partners, finding Benchmarking collaborators willing to participate in the benchmarking processes, exchanging all possible background information beforehand, thus being able to start covering the relevant areas. The rest with mean of three seem to be coupled with uncertainties on

$2.7241 \quad 1.27885 \quad 4$

$2.7778 \quad 1.50214 \quad 5$

$2.8889 \quad 1.42325-7$

$2.9630 \quad 1.25519$

$2.9655 \quad 1.08505$

$3.2222-1.25064-10$

$\begin{array}{lll}3.5172 & 1.35279 & 12\end{array}$

$\begin{array}{lll}3.5517 & 1.40372 \quad 13\end{array}$

$3.5926 \quad 1.47438 \quad 14$

$\begin{array}{lll}3.6276 & 1.22675 \quad 15\end{array}$

$3.8276 \quad 1.22675 \quad 16$

$4.0000 \quad 1.30931 \quad 17$ their influence on the success of the benchmarking technique as a tool of continuous improvement.

\section{SUMMARY, CONCLUSIONS AND RECOMMENDATIONS}

\section{A. Summary of Findings}

Data was collected from 24 parastatals of the Ministry of Agriculture whose performance was at extremes. The collected data was analyzed and interpreted in line with the objectives of the study, namely, to establish the extent of adoption of benchmarking technique as a tool for continuous improvement in the Ministry of Agriculture Parastatals in Kenya and the challenges facing the Ministry of Agriculture parastatals in Kenya in the use of benchmarking technique as a tool for continuous improvement. There was a response rate of $56 \%$. The research methodology was based on a survey design given the population was 24 parastatals.

A questionnaire with open ended and closed questions was developed by the researcher and used in data collection. Summary is based on the research questions as follows.

Continuous improvement adopts an approach to improving performance which assumes more and smaller incremental improvement steps. In continuous improvement it is not the rate of improvement which matters but the momentum of improvement. It was found out that congruence parastatals products and services with the market were good but not excellent. The rating of the continuous improvement systems in the parastatals was also rated as good. This confirms [18] conclusion that the Kenyan people are not receiving value for their money instead what can be seen are poorly performing state corporations and government departments full of corruption. Some of the external drivers of change were found to be the marketplace, consumers and Legislation. The Internal drivers of change in the parastatals were also found to be actual performance and monitoring systems. It was found that most parastatals had systems that facilitate the 
systematic comparison and evaluation of practice, process, and performance with any "best practices or smarter" institutions in improvement and self - regulation. Some of the systematic comparison and evaluation of the practice, process and performance that have been adopted to a great extent were found to be analysis of results; measurement of own and benchmarking partners' performance level, both for comparison and for registering improvements; comparison of performance levels, processes and practices; the careful study of your own practices and performance; and lastly a thorough search to identify best- practice - organizations.

Some of the systematic factors that influence the success of the benchmarking /process of emulating the best practices in the parastatals to a very great extent include the objective identification of opportunities and bottlenecks; the organization's own former performance; the added value offered by the method /cost-benefit analysis; the support of the method to the outside world. This is in line with [19] observation that benchmarking may be a one-off event but is often treated as a continuous process in which organizations continually seek to challenge their practices influenced by a number of factors.

A better understanding of practice, performance and insights to a very great extent is what the parastatals have achieved in the participation in any benchmarking exercise. Improved networking and benchmarking information are minor objectives of the participation.

The comparisons in benchmarking can be done and modelled in a number of ways. It was found that most of the parastatals agreed with the 2006/2007 performance ranking of the Ministry of Agriculture parastatals.

It was found that the major source of data and information in benchmarking is through direct contact; and the reference point for the comparisons are performance indicators that is the statistical measures and online data; as opposed to the specification, codes of practice, descriptors and examples and action research which is focused surveys supported by discussion. The four types of benchmarking which are currently in use are internal benchmarking, competitive/performance benchmarking, external benchmarking, and strategic benchmarking. It was also found that the three most critical factors that influence the choice of the various benchmarking tools and scope of the parastatals are compatibility with local conditions, time, and resource availability, and lastly the limited duration for comparability of the parastatals and processes.

Among the nine key challenges that have faced the Ministry of Agriculture parastatals in Kenya in the use of benchmarking technique as a tool for continuous improvement to a great extent include; analyzing and gaining a deeper understanding of one's own processes; requesting for initial performance information about the process in question before selecting a benchmarking partner, performing and benchmarking visits in teams to ensure that people complement each other in terms of teams and skills and interested and contributed to creating ownership in the parastatals and comparability of companies and their operation processes.

\section{B. Conclusion}

The study concludes that Firstly, there is a positive and statistically significant relationship between BPR strategy and performance of food manufacturing companies in Kenya whereby $63.9 \%$ of variations in the overall firm performance are attributed to the changes in the BPR strategy namely resources mobilization for BPR, sponsorship and commitment, BPR cross functional teams, analytical processes selection, BPR prototypes, management of reengineered processes, clear BPR definition and vision. The results therefore support the anchoring theory of resource advantage theory.

\section{Recommendations}

Based on the results from the data analysis and findings of the research, a summary of conclusions was arrived at as enumerated below.

Continuous improvement adopts an approach to improving performance which assumes more and smaller incremental improvement steps. The rating of the continuous improvement systems in the parastatals was also rated as good. The internal drivers of the change in the parastatals were also found to be actual performance and monitoring systems.

It was found that most parastatals had systems that facilitate the systematic comparison and evaluation of practice, process, and performance with any "best or smarter" institutions in improvement and self - regulation.

It was also established that the systematic factors that influence the success of benchmarking to a very great extent included the objective identification of opportunities and bottlenecks, the organization's own performance; the added value offered by the method /cost benefit analysis; improved networking and benchmarking information are minor objectives of the participation.

The comparisons are done through systematic evaluation of alternatives and adopting successful comparing processes with those of competitors in the Ministry. To a very great extent, the comparisons are modeled through independent self-referencing, followed by collaborative group partnership, then through brokered models involving an individual or agency intervening.

It was also found out that the four types of benchmarking which are commonly in use are internal benchmarking, competitive/ performance benchmarking, external benchmarking, and strategic benchmarking. It was also revealed that the three most critical factors that influence the choice of various benchmarking tools/technique and scope in the parastatals are compatibility with local conditions, time and resource availability and lastly the limited duration for comparability of the parastatals and processes.

Finally, the five key challenges that face the Ministry of Agriculture parastatals in Kenya in the use of benchmarking technique as a tool for continuous improvement to a great extent include; analyzing and gaining a deeper understanding of own processes - a need for understanding own processes by analyzing and understanding the parastatals own processes, requesting initial performance information about the processes in question before selecting a benchmarking partner, performing the benchmarking visits in teams to ensure that people complement each other in terms of skills 
and interests and contribute to creating ownership in the parastatals comparability of companies and their operation processes, seeking aid and support from sources and institutions that might be able to point to and convince potential partners.

\section{Limitations of Study}

The following factors were the greatest hurdles while conducting the study; Time: It took long when collecting questionnaires because some of the respondents kept them and never bothered to answer. Irritancy: Some of the respondents had no information hence giving out data which was not satisfactory. Transportation: Due to poor means of communication it too long to visit all branches and this led to late arrivals when managers had left for meetings or left after working hours. Literature review: Due to poorly equipped libraries on ICT and e-operations it took long to get the required data and literature. The following challenges need to be addressed within the Ministry of Agriculture parastatals; comparability of the parastatals and their operation processes, seeking aid and support from sources and institutions that might be able to point to and convince potential partners, finding benchmarking collaborators willing to participate in the benchmarking studies, applying a systematic procedure whereby a large number of potential benchmarking partners are scanned for relevance and high performance, exchanging all possible background information beforehand. The other challenges with a mean of three seem to be coupled with uncertainties on their influence on the success of the benchmarking technique as a tool of continuous improvement.

\section{E. Suggestions for Further Research}

Areas of further studies that were identified include a similar study to be carried out on other ministries in the Kenyan government. Further research should be undertaken to determine how benchmarking can contribute to a company's financial performance and credit risk management. A study should also be done to assess the adoption and challenges facing the other parastatals in Kenya in the use of benchmarking as a continuous improvement tool.

\section{REFERENCES}

[1] Camp, R.C., (1998) Benchmarking: The Search for industry best practices that lead to superior performance. ASQC Quality press, Milwaukee WI.

[2] Watson, D. (1996), "Quality assessment and Self-Regulation: The English Experience, 1992-94”, Higher Education quarterly, volume 49 Number 4, pp 326-40.

[3] Elcock and Howard (2006)" The public Interest and Public Administration" Vol 26. Issue 2, pp 101-109.

[4] Cartin, T.J., (2000). Principles and Practices of Organization Performance Excellence. Court, D and Ghai, D - Eds (1974) "Education, society and development: New perspectives from Kenya. Nairobi, Oxford University press.

[5] Magutu, P., Mbeche, I., Nyamwange, S.O., \& Nyaoga, R. (2011). A Survey of Benchmarking Practices in Higher Education in Kenya: The Case of Public Universities. IBIMA Business Review Journal.

[6] Amolo T.O (2002), "Benchmarking the Order Delivery Process in the Oil Industry", University of Nairobi.

[7] Jackson, N.J., (1998), "Academic regulation in U.K. higher education Part III-The Idea of Partnership in Trust" Volume 6 number 1 (1998) pp 5-18 Quality assurance in Education.

[8] http://www.kilimo.go.ke/.
[9] Garvin. B.A (1993), "Building a Learning Organization" Harvard Business Review, Vol 71 number 4 pp 78-91.

[10] Folz and David H. (2004) "service Quality and benchmarking the performance of Municipal services" Public Administration Review Vol 64, Issue 2 pp 209-220.

[11] APQC (1993), American Productivity and Quality Centre: Basics of Benchmarking, Houston, Texas.

[12] Johnson, B., Chambers, M., 2000a), "Expert panel identifies activities and performance measures for food service benchmarking", Journal of the American Dietetic Association, Vol 100 No 6 pp. 692.

[13] Battaglia, J. Jr, Musar R. (2000). "Picking the Right Benchmarking", Journal of Accountancy, Vol 190 No 2, pp 63.

[14] Norman G. (2001), Production and Operations Management, 7th Edition.

[15] Rosco Sekerana U (1975). "Research Methods for Business" a skill Building approach, 2nd ed wiley \& Sons, New York.

[16] Kaewsonth \& Harding, 1992, Eds Management in Developing Countries, Routledge, London.

[17] Appleby, A., (1995), "Benchmarking Theory: a framework for the business world as a context for its application in higher education", in Smith H. Armstrong, M. and Brown, S. (Eds), Benchmarking and Threshold Standards, Kogan page, London.

[18] Aosa (1993) Strategic practices in manufacturing practices in Kenya. Unpublished thesis University of Nairobi, pp 56-67.

[19] Mahmoud M. Yasin, (2002), Benchmarking: An international Journal, Vol 9 No 3, pp 217-43. 